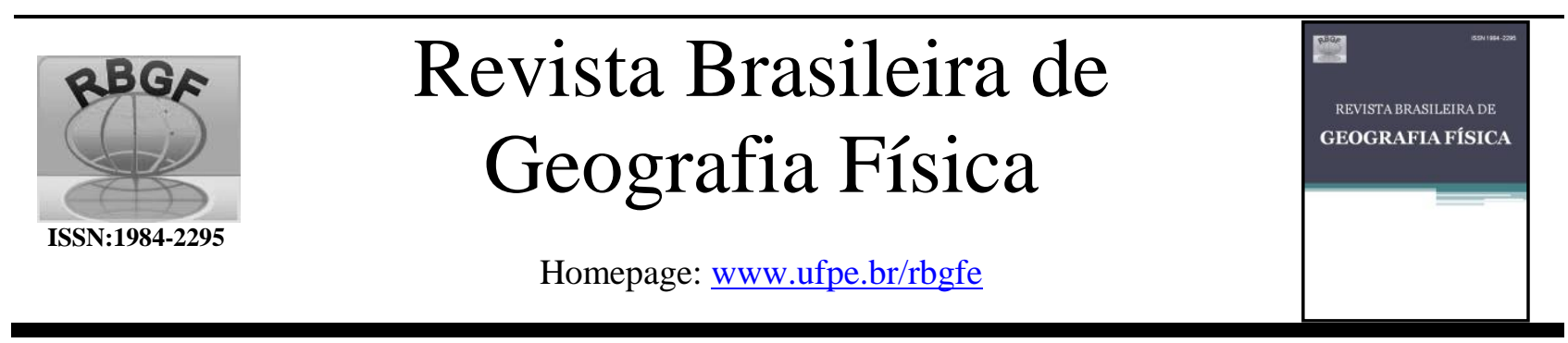

\title{
Parâmetros físico-ambientais em áreas com possibilidade de ocorrência de solos coesos da depressão do São Francisco-BA: O caso da Fazenda Caracol-BA
}

\author{
Joildes Brasil ${ }^{1}$, Selma Simões de Castro ${ }^{2}$
}

\begin{abstract}
${ }^{1}$ Doutoranda do Programa de Pós-Graduação em Geografia da Universidade Federal de Goiás-UFG, Instituto de Estudos Socioambientais, - IESA, Campus Samambaia, CEP 74001-970 Goiânia, Goiás, Brasil.(62) 3521 1095. Autor correspondente: joildesbrasil@ yahoo.com.br. ${ }^{2}$ Professora Doutora da Universidade Federal de Goiás-UFG, Instituto de Estudos Socioambientais, - IESA, Campus Samambaia, CEP 74001-970 Goiânia, Goiás, Brasil.(62) 3521 1095. selma.castro@pq.cnpq.br.
\end{abstract}

Artigo recebido em 21/06/2016 e aceito em 19/10/2016

\section{R E S U M O}

O caráter coeso do solo é utilizado pelo Sistema Brasileiro de Classificação de Solos, para solos que apresentam horizonte extremamente endurecido entre $30-70 \mathrm{~cm}$ de profundidade, caracterizado por forte adensamento natural, cuja a origem ainda não é conclusiva, embora se destaque o processo de silicificação e de argiluviação como as principais. Ocorrem em regiões semiáridas e áridas, como no NE brasileiro, onde estão associados aos tabuleiros costeiros sustentados por sedimentos terciários e quaternários, como os do Grupo Barreiras. Fora dessa Formação são pouco conhecidos, como na Depressão do São Francisco-BA onde solos com horizontes endurecidos sugerem presença de solos coesos. Nesse sentido, o presente artigo se propõe a discutir a relação entre o caráter coeso nos solos e os parâmetros físico-ambientais da paisagem, mais especificamente da Fazenda Caracol-BA, em que tais horizontes vêm dificultando a atividade agrícola. A pesquisa foi realizada a partir da construção de um banco de dados georreferenciados no software Arcgis 10.1 relativos a altitude e declividade gerados a partir de imagens SRTM (TOPODATA).Os dados de solos foram do Relatório de Levantamento Pedológico da própria fazenda e os dados de uso e cobertura foram gerados a partir da classificação das imagens Landsat-8. Entre os parâmetros analisados, destaca-se o papel da sílica e da argila. A partir das interpolações de ambas as variáveis, foram identificados núcleos de acumulação de argila entre 0-20 e 20-40 cm de profundidade, e de sílica a partir de $100 \mathrm{~cm}$ de profundidade, indicando possível ocorrência do caráter coeso nos solos estudados, embora diferente dos preconizados pelo SiBCS.

Palavras-chave: Caráter Coeso, Parâmetros Físico-Ambientais, agentes cimentantes.

\section{Physical and environmental parameters of the areas with possibility of cohesive soils in the depression of the San Francisco, Bahia: The case of Caracol Farm}

\begin{abstract}
A B S T RA C T
The cohesive nature of the soil is used by the Brazilian System of Soil Classification, for soils with extremely hardened horizon between $30-70 \mathrm{~cm}$ deep, characterized by strong natural densification, whose origin is still not conclusive, although it highlighted the process of silicification and Argilluviation as the main. Occur in semi-arid and arid regions, such as the Brazilian NE, which are associated with coastal tablelands supported by tertiary and quaternary sediments, such as the Barreiras Group. Out of this formation are not well known, as in the Depression of the San Francisco-BA where soils with hardened horizons suggest the presence of cohesive soils. In this sense, this article aims to discuss the relationship between the cohesive character in the soil and the physical and environmental parameters of the landscape, specifically the Treasury Snail-BA, where these horizons have hindered agricultural activity. The survey was conducted from building a georeferenced database on 10.1 Arcgis software for the altitude and steepness generated from SRTM images (TOPODATA) . The soil data were from the farm itself Pedological Survey Report and data use and coverage were generated from the Landsat-8 image classification. Among the analyzed parameters, there is the role of silica and clay. From the interpolations of both variables were identified clay accumulation cores between $0-20$ and $20-40 \mathrm{~cm}$ deep, and silica from $100 \mathrm{~cm}$ depth, indicating possible occurrence of cohesive character in the soils, although different from recommended by $\mathrm{SiBCS}$..
\end{abstract}

Keywords: Character Cohesive, Physical Environmental Parameters, cementing agents 


\section{Introdução}

Solos com caráter coeso vêm sendo estudados desde a década de 1950 no Brasil, cujos estudos pioneiros foram realizados nos estados do Espírito Santo e Rio de Janeiro, onde foi identificada presença de um horizonte extremamente adensado, com alto grau de coesão (resistência tênsil), principalmente nas profundidades entre 30 e $70 \mathrm{~cm}$, compondo perfil de solo aparentemente apedal ou apédico (sem agregação).

$\begin{array}{clcc}\text { Ainda } & \text { que } & \text { existam pesquisas já } \\ \text { consolidadas } & \text { no } & \text { mundo } & \text { quanto ao }\end{array}$ desenvolvimento do caráter coeso no solo, ainda persistem dúvidas entre os pesquisadores quanto à sua gênese e aos fatores condicionantes de sua formação e evolução, incluindo-se aí os relativos ao meio físico e biótico, sobretudo no Brasil. A maioria dos poucos autores que os estudaram no País (Raij e Camargo, 1973; Anjos, 1985; Ribeiro, 1986; Ker, 1997; Giarola, 2002; Araujo Filho, 2003) apontam que entre os principais processos responsáveis por sua formação encontra-se o entupimento dos micros/macroporos por frações finas de argila (argiluviação) e também por sílica (silicificação), os quais, agindo simultaneamente ou não, constituem-se em prováveis agentes promotores do adensamento e seu caráter coeso. Em geral tais processos ocorrem em regiões semiáridas e áridas, em geral planas, para onde convergem fluxos hídricos superficiais e subsuperficiais.

Segundo o Ministério do Meio Ambiente (MMA, 2014), os parâmetros ambientais são indicadores estatísticos selecionados que representam ou resumem alguns aspectos do estado do meio ambiente, dos recursos naturais e de atividades humanas relacionadas. Em outras palavras, os parâmetros ambientais são ferramentas que auxiliam na identificação de padrões ambientais, onde é possível criar estratégias de avaliação de determinado fenômeno, neste caso, a ocorrência dos solos coesos.

Desse modo e de forma sucinta, o presente artigo aborda resultados de trabalhos realizados pela primeira autora (Brasil, 2012; Brasil, 2014) acerca da presença de solos coesos nos limites da Depressão do São Francisco, com destaque a fazenda Caracol, onde foram primeiramente identificados, a partir do mal desempenho de um plantio de eucalipto associado à presença de camada adensada. Segundo Brasil (2012) e Alves (2011) foi possível identificar a presença de
Latossolo Amarelo nessa fazenda, alvo do plantio, apresentando um horizonte extremamente duro, que estaria causando um impedimento ao crescimento das raízes e levando a mortandade dos eucaliptos. Também se constatou Argissolo Amarelo com adensamento no horizonte Bt A seguir, focam-se os resultados espacializados para o substrato rochoso, o relevo, o clima, vegetação, a sílica e argila, de modo a correlacioná-los à ocorrência dos solos com horizontes endurecidos e adensados e assim identificar os parâmetros físicoambientais indicadores de sua ocorrência.

Diante o exposto, o artigo tem como objetivo apresentar e discutir parâmetros físicoambientais, relacionados à ocorrência dos solos coesos na região da Depressão do São Francisco, no contexto local da fazenda Caracol, visando sua caracterização ambiental em nível local, na tentativa de identificar padrões que justifiquem a ocorrência desse tipo de solo.

\section{Material e métodos}

\section{Caracterização da Área de estudo}

A Fazenda Caracol pertence ao grupo Granflor - Gestão Empreendimentos Florestais e se localiza no município de Cotegipe, no Estado da Bahia, abrangendo uma área de aproximadamente 120.000ha. Está totalmente inserida na unidade geomorfológica da Depressão do São Francisco (Figura 1). O embasamento geológico é representado por rochas metamórficas que integram o Grupo Bambuí, que apresenta contribuição de calcário, as quais estão recobertas por sedimentos recentes de origem quaternária, de textura areno-argilosa.

Os solos identificados na fazenda apresentam predominância de Latossolos e Neossolos Quartzarênicos de acordo com o mapeamento de reconhecimento de solo na escala de 1:100.000 da fazenda Caracol-BA, cujas cores são amareladas, o que é comum nos solos da região. Em menor ocorrência, encontram-se Argissolos, Plintossolos e Gleissolos. Quanto às características químicas, os solos apresentam baixos teores de nutrientes essenciais como Fósforo, Potássio, Cálcio e Magnésio, com predominância do Alumínio no complexo de troca. 

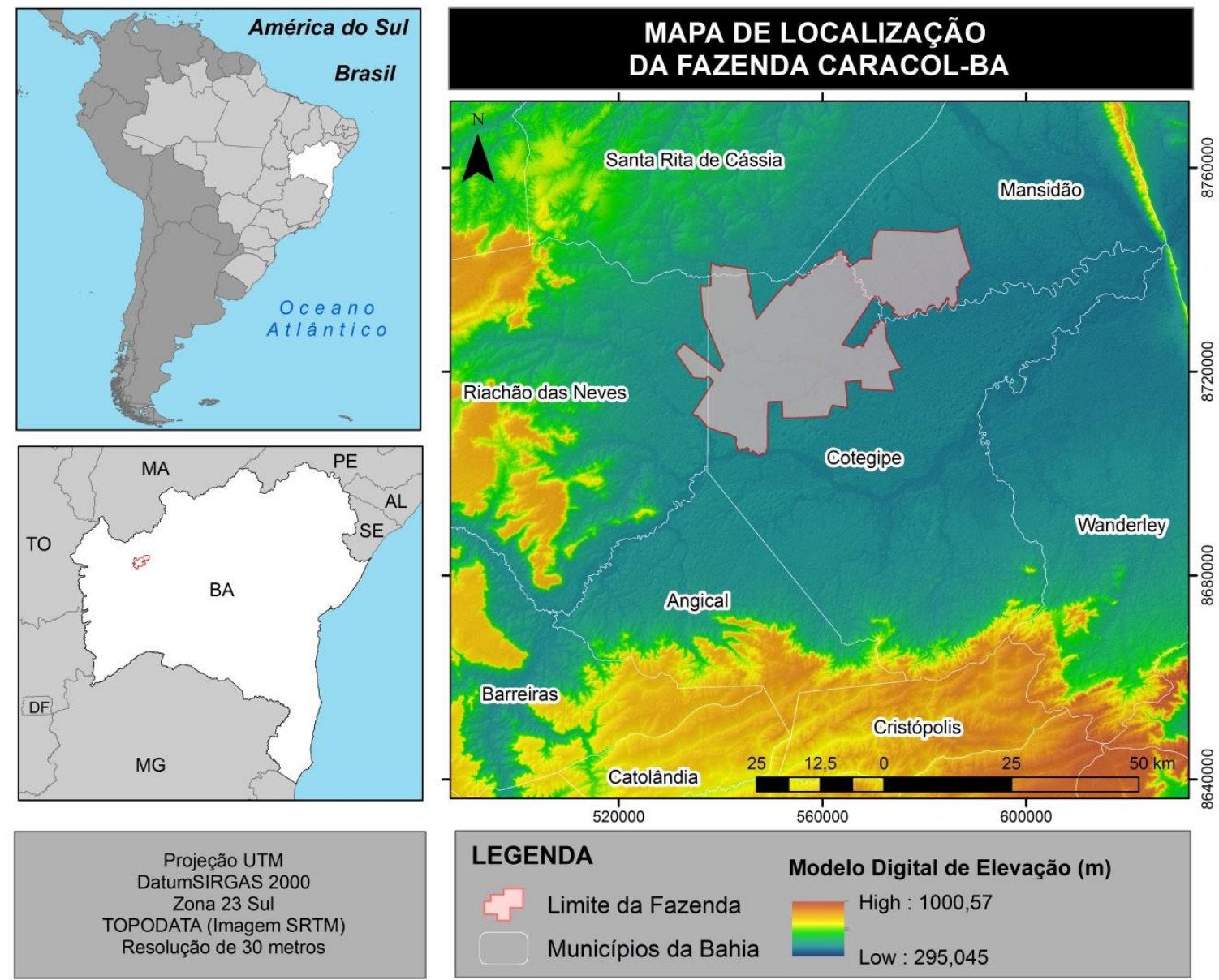

Figura 1. Mapa de localização da Depressão do São Francisco-BA e da Fazenda Caracol-BA, área de pesquisa.

A cobertura vegetal natural da área era do tipo Cerrado, que foi substituída na última década pelas culturas anuais (soja, milho, sorgo e algodão), além de pastagens (B. decumbens cv. Basilisk, B. brizhanta cv. Marandu, P. maximum cv. Massai e Andropogon Gayanus). Segundo relato dos gestores da fazenda, o objetivo do atual Plano de Manejo é a realização de atividades integradas, principalmente iLP (lavoura-pecuária) e iFP (silvopastoril). Além das culturas citadas, também foi implementado florestamento por eucalipto em áreas experimentais, contudo o plantio apresentou uma alta taxa de mortalidade. A partir de estudos mais detalhados, foi possível diagnosticar que o Latossolo Amarelo foi o alvo do plantio, e nele a presença de um horizonte extremamente duro, que estaria causando um impedimento ao crescimento das raízes e levando a mortandade dos eucaliptos. Esse horizonte foi relacionado ao caráter coeso(Alves, 2011).

Segundo a classificação climática de Köppen, a área apresenta clima do tipo Aw - clima tropical de savana com estação seca de inverno. Portanto, não se trata de clima semiárido nem árido. Mas, o clima apresenta longos períodos de estiagem, aos quais se atribui baixo volume de chuvas e umidade relativa, o que se costuma relacionar à intensificação da coesão do solo, permanecendo apenas as espécies mais resistentes ao déficit hídrico. No período das chuvas (dezembro a março), apresenta-se um cenário oposto, o solo atenua a coesão (friabilidade) e torna-se menos resistente à penetração, favorecendo o cultivo.

A formação de horizontes adensados está relacionada a esses ambientes com períodos úmidos e secos, o que favorece a dissolução e precipitação de agentes cimentantes, que por sua vez preenche os poros do solo, aumentando a densidade, resultando na formação de horizontes adensados.

\section{Metodologia}

A base de dados gerada corresponde aos arquivos no formato shapefile dos atributos físicos, a saber: geologia, hipsometria, declividade, solos (classe de solos, teor de argila e sílica) e uso do solo e cobertura. Esses planos de informação foram manipulados em ambiente SIG no software ArcGis 
10.1, para que fosse possível uma análise integrada desses componentes da paisagem para a correlação espacial.

Os dados de geologia da área de pesquisa foram adquiridos no sistema GEOBANK, disponível gratuitamente no sítio do Serviço Geológico do Brasil - CPRM. Na ausência de cartas de maior detalhe, foram utilizados os dados geológicos em nível nacional na escala de 1.1.000.000 apenas como referência. Para auxiliar a análise foi feita uma revisão de literatura utilizando-se principalmente o livro sobre Geodiversidade do Estado da Bahia.

O modelo de hipsometria foi gerado a partir do MDT (Modelo Digital de Terreno) da imagem SRTM, com resolução espacial de $30 \mathrm{~m}$, referente a folha 11S45_ZN do projeto TOPODATA. Na elaboração do modelo de declividade foi preciso estabelecer as classes de declive predominantes na área de pesquisa. No Arcgis 10.1, com ferramenta slope foi gerado a partir do MDT (Modelo Digital de Terreno) a declividade da área de estudo, representada em classes na forma de porcentagem.

A análise de uso e cobertura foi realizada através de imagens do Sensor TM (Thematic Mapper) dos satélites Landsat-5 e Landsat- 8 , com resolução espacial de 30 metros. No fim do ano de 2012 o satélite Landsat-5 foi desativado e lançado no início de 2013 o Landsat-8. Em função disso, foram utilizadas imagens de ambos os satélites, de modo a que fossem adquiridas as informações pertinentes ao recorte desta pesquisa.

Com base nos dados do Relatório de Levantamento Pedológico de Reconhecimento de Alta Intensidade, Classe de Capacidade de Uso e Unidade de Manejo Operacional da Fazenda Caracol, foi realizada uma tabulação com os dados do teor da argila das 79 perfis de solo descritos, enfatizando-se as profundidades de: $0-20$ e $20-$ $40 \mathrm{~cm}$, uma vez que o caráter coeso ocorre nos primeiros horizontes do solo (Fonseca, 1986; Jacomine, 1996; Rezende, 2000) e levando em consideração o papel da argila no processo de coesão (Ribeiro, 1986, Araújo Filho et al., 2001). Cada perfil de solo foi georreferenciado de acordo com o sistema de projeção UTM. Após a tabulação os dados foram exportados para o software Arcgis 10 , onde foram realizadas as interpolações com auxílio da ferramenta Spatial Analyts e do interpolador Natural Neighbor (Vizinho Natural) o que permitiu a elaboração dos mapas de isovalores de argila nas profundidades indicadas, acrescentando-se a de $100 \mathrm{~cm}$ para os teores de sílica, devido os dados analíticos indicarem aumentos em alguns perfis nessa profundidade que contaram com essa análise.

\section{Resultados e discussão}

\section{Parâmetros Físicos Ambientais}

\section{Geologia}

A grande maioria dos estudos sobre solos coesos informam que o caráter coeso se desenvolve predominantemente em sedimentos do Grupo Barreiras (Anjos 1985; Ribeiro, 2001), que ocorrem na unidade geomorfológica dos Tabuleiros Costeiros, no Nordeste Brasileiro, como já exposto. O Grupo Barreiras se destaca na região norte e nordeste do litoral brasileiro, e essa continuidade física conduz, entre outras, a especificidades regionais e locais, o que contribui para que esse grupo seja tão heterogêneo. Segundo Jacomine apud Nunes et al. (2011). os sedimentos do Grupo Barreiras ocorrem geralmente em altitudes entre 20 e $200 \mathrm{~m}$, mas são comuns casos de altitudes mais elevadas, como em algumas regiões nos Estados do Rio de Janeiro e da Bahia. Os sedimentos do Grupo Barreiras têm sua origem associada a sedimentos detríticos, siliciclásticos, de origem fluvial e marinha, mal selecionados, podendo ser pouco ou não consolidados, apresentando cores variegadas, com textura formada por areias finas a grossas e mineralogia representada predominantemente pelas caulinitas (Nuneset al.,2011).

Todavia, os solos da Fazenda Caracol-BA foram formados noutra unidade geológica, inserida no Domínio das Coberturas Cenozóicas DetritoLateríticas. Segundo o Atlas de Geodiversidade da Bahia (CPRM, 2010) esse domínio enquadra-se na unidade geológico-ambiental dos Depósitos detrito-lateríticos que na sua origem passaram pelo processo de lateritização sobre rochas de composições diversas e sem a presença de crosta ferruginosa. O relevo associado a essa unidade também é bastante variado, mas na área da Fazenda é formado por superfícies aplainadas, às quais se associam principalmente aos Latossolos Amarelos e Neossolos Quartzarênicos.

No tocante à ocorrência dos solos coesos em outras unidades geológicas, que não o Grupo Barreiras, pode-se aventar algumas possibilidades. No quadro 1 são apresentadas algumas características geoambientais do Grupo Barreiras e das Coberturas Cenozoicas Detrito-Lateríticas, uma vez que nesta última unidade predomina na Depressão do São Francisco-BA, e em particular na Fazenda Caracol. 


\begin{tabular}{|c|c|c|c|}
\hline \multicolumn{2}{|c|}{ Características } & $\begin{array}{l}\text { Coberturas Cenozoicas Detrito- } \\
\text { Lateríticas }\end{array}$ & Grupo Barreiras \\
\hline \multirow{4}{*}{ Idade } & Eon & Fanerozóico & Fanerozóico \\
\hline & Era & Cenozóico & Cenozóico \\
\hline & Período & Neogeno & Paleogeno \\
\hline & Época & Mioceno & Paleoceno \\
\hline \multicolumn{2}{|c|}{ Litologia } & $\begin{array}{l}\text { Conglomerado, Laterita, Depósitos de } \\
\text { areia, Depósitos de argila }\end{array}$ & $\begin{array}{l}\text { Argilito arenoso, Arenito } \\
\text { conglomerático }\end{array}$ \\
\hline \multicolumn{2}{|c|}{ Classe de Rocha } & Ígnea, Material superficial & Sedimentar \\
\hline \multicolumn{2}{|c|}{ Textura } & Variável verticalmente & $\begin{array}{l}\text { Variável de arenoso a } \\
\text { argilo-siltoso }\end{array}$ \\
\hline \multicolumn{2}{|c|}{$\begin{array}{c}\text { Domínio } \\
\text { Geoambiental }\end{array}$} & $\begin{array}{l}\text { Domínio das coberturas cenozóicas } \\
\text { detrito-lateríticas associadas aos } \\
\text { interflúvios planálticos }\end{array}$ & $\begin{array}{c}\text { Domínio dos sedimentos } \\
\text { cenozóicos pouco a } \\
\text { moderadamente } \\
\text { consolidados associados a } \\
\text { tabuleiros. }\end{array}$ \\
\hline \multicolumn{2}{|c|}{ Relevo } & Superfícies Aplainadas Conservadas & Tabuleiros \\
\hline \multicolumn{2}{|c|}{$\begin{array}{c}\text { Sistema de } \\
\text { Sedimentação }\end{array}$} & Leque Aluvial & Fluvial Entrelaçado \\
\hline
\end{tabular}

Quadro 1. Características geoambientais das Coberturas Cenozóicas Detrito-Lateríticas e do Grupo Barreiras, unidade onde os solos coesos são registrados.

A partir do Quadro 1, observa-se que as Coberturas Cenozoicas Detrito-Lateríticas são potencialmente propícias à formação de camadas silicificadas, como as identificadas em toda área da Depressão do São Francisco próximas a áreas de aluviões. Segundo o mapa geológico da Bahia essa mesma unidade é denominada de "Coberturas detrito-lateríticas ferruginosas" onde predominam sedimentos de textura areno-argilosa correlacionados ao período Quaternário. Os Latossolos que se formam nessa unidade apresentam acumulações de ferro (em alguns casos, concreções) que se manifestam no solo e podem variar de espessura e grau de dureza. A fração argila no Latossolo podem variar de 15 à $80 \%$, sendo composta principalmente por caulinita, goethita, hematita e gibbsita (KER, 1997).

De acordo com Alves (2011), as argilas presentes no Latossolos Amarelos da área de estudo são tipo 1:1, ou seja, do grupo da caulinita.
O autor ainda afirma que "a identificação da presença de caulinita, desassociada de outras argilas silicatadas, deixa o solo muito uniforme em sua organização, de maneira que as camadas planares da caulinita se sobrepõem" (Alves, 2011, p. 21). Nesse sentido, a estrutura planar da caulinita e seu empilhamento nas camadas do solo é considerado como um dos fatores formadores dos horizontes coesos.

\section{Hipsometria}

Conforme pode ser observado no mapa hipsométrico (Figura 2), as menores altitudes são de 415 a 430m, que ocorre em 15,14\% da área da fazenda, principalmente próximas aos canais fluviais e no setor nordeste, onde encontram-se os Neossolos Quartzarênicos. As duas primeiras classes altimétricas (415-430 e 430 - 435m) correspondem a $43,91 \%$ da área. 


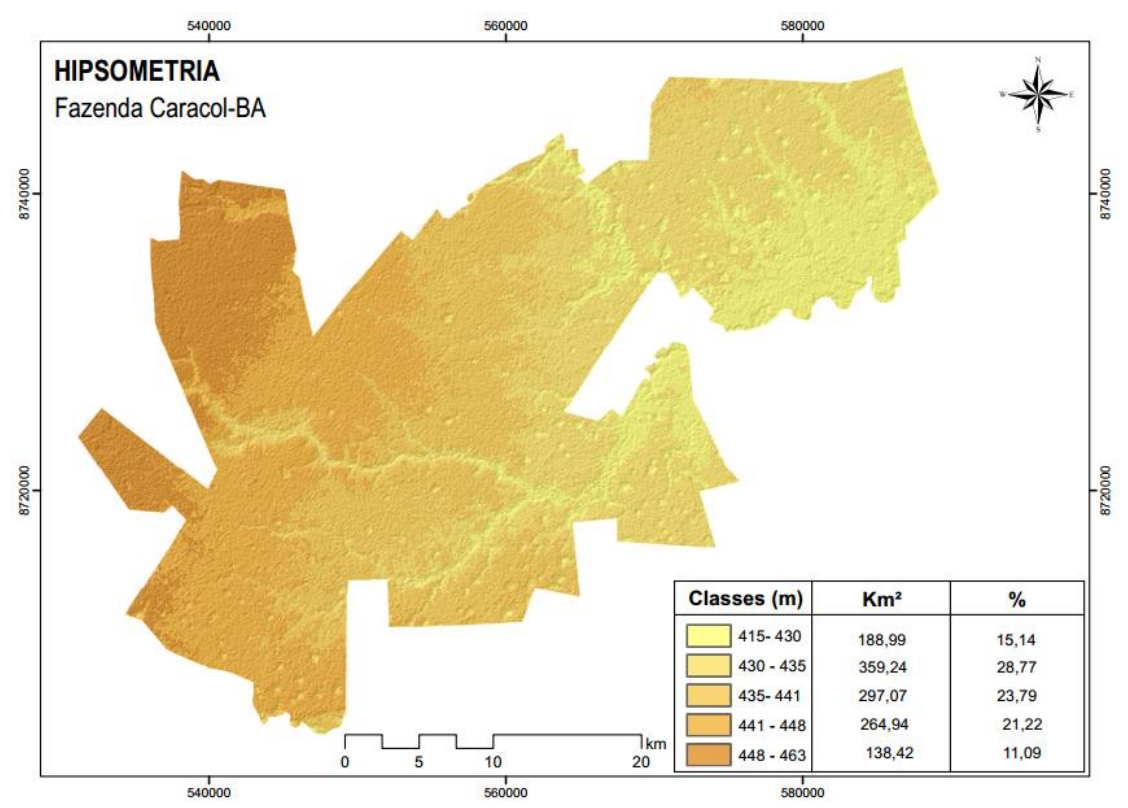

Figura 2. Mapa hipsométrico da fazenda Caracol-BA.

$\mathrm{Na}$ paisagem observa-se também uma concentração de lagoas, principalmente no setor nordeste da fazenda, sobretudo em altitudes superiores aos dos canais fluviais, o que permite concluir que os canais já ultrapassaram o limite das rochas mais consolidadas, que se configuram como nível de base das lagoas. Assim, as lagoas podem estar associadas a dificuldade de drenagem interna, o que também poderia estar associado à presença de horizonte coeso.

A classe de 435 - 441m situa-se numa zona de transição entre as áreas mais rebaixadas com Neossolo Quartzarênico e a áreas um pouco mais elevadas onde domina o Latossolo Amarelo, e corresponde a 23,79\% da área. Esse incremento da altitude se dá no sentido leste - oeste, essa mesma área recebe destaque quanto aos teores elevados da fração argila entre as profundidades de $0-40 \mathrm{~cm}$, como será apresentada nos tópicos adiante.

As classes de 441- 448m e 448-463m correspondem, respectivamente, a $21,22 \%$ e $11,09 \%$ da área e compreendem as maiores altitudes registradas na fazenda. Nelas, predomina o Latossolo Amarelo, com exceção ao setor sudeste onde o Neossolo Quartzarênico também ocorre. Esses setores mais altos correspondem a superfícies geomórficas residuais, mais antigas, onde havia um ambiente propício à maior evolução geoquímica dos solos dessa área.

\section{Declividade}

O relevo da fazenda Caracol é predominantemente plano, como pode ser observado no mapa de declividade (Figura 3). As duas classes com menores valores de declividade representam $65,91 \%$ da área total da Fazenda, correspondendo a classe de relevo plano, enquanto que os maiores valores de declividade ficam em torno de $8-14 \%$, equivalem a $2,03 \%$ da área de estudo.

O relevo plano confere estabilidade às vertentes, indicadas como de baixo gradiente altimétrico na área. A relação entre solos e a declividade permite constatar que a classe dos Latossolos Amarelos ocorre predominantemente nas áreas com declividade entre 1 e 3\%. Os Neossolos Quartzarênicos também ocorrem no mesmo intervalo de declividade, sendo que o que distingue mais nitidamente essas duas classes de solo é a altimetria, como já exposto. Próximos aos canais fluviais é possível observar uma mudança nesse padrão de declividade, onde o relevo passa de "plano" para "suave ondulado", resultado do entalhamento fluvial.

Quanto a ocorrência dos solos coesos e a declividade, não foi identificado nenhum padrão, uma vez que o declive é bastante homogêneo em toda área, exceto nas áreas próximas aos cursos d'água. Entretanto, a declividade auxiliou no limite entre os Neossolos e os Latossolos. Não foram mapeados os Gleissolos, mas as áreas com menores declividades próximas aos canais (planícies fluviais) são favoráveis à sua ocorrência. 


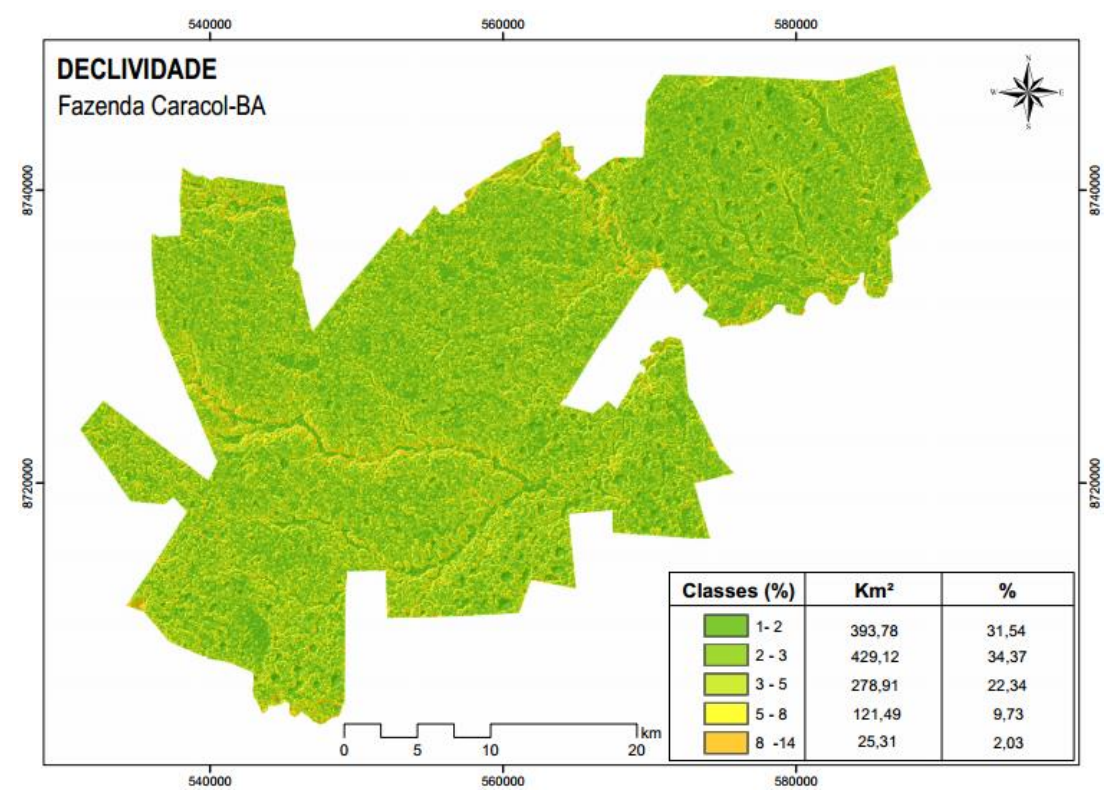

Figura 3. Mapa de declividade da fazenda Caracol.

\section{Solos}

De acordo com o mapa de solos da fazenda Caracol (Figura 4) foram identificadas duas classes dominantes de solos, o Latossolo Amarelo (LA) e o Neossolo Quartzarênico (RQ). A unidade de mapeamento identificada corresponde ao Latossolo Amarelo Distrófico (LAd3 e LAd4) e à associação Neossolo Quartzarênico Órtico e Latossolo Amarelo Distrófico (RQo + LAd5). A unidade LAd4 corresponde predominantemente ao LATOSSOLO AMARELO Distrófico típico, com textura média arenosa e que ocorre em áreas de relevo ligeiramente côncavo. $\mathrm{Na}$ área de abrangência dessa unidade, foram identificados horizontes adensados em perfis de LATOSSOLO AMARELO Distrocoeso plíntico (LAdx), não representados no mapa devido a escala adotada. A unidade LAd3 tem como solo predominante o LATOSSOLO AMARELO Distrófico típico associado ao LATOSSOLO AMARELO Distrófico plíntico, localizados em relevo plano, porém rebaixado em relação ao anterior, em que alguns casos o caráter plíntico se manifesta, devido a ascensão e rebaixamento do lençol freático. $\mathrm{Na}$ área de abrangência dessa unidade também foram identificados perfis de solo com horizontes coesos em ARGISSOLO AMARELO Distrófico petroplíntico (PAd), com caráter coeso no horizonte Bt1 $(19-51 \mathrm{~cm})$.

Por ocorrerem de forma restrita e localizada, tantos os LAdx (identificados na unidade LAd3) como os PAd, não foram mapeados. Tais ocorrências ainda que restritas tem se apresentado como um problema, dada a presença de horizonte coeso, e que afetaram diretamente a plantação de eucalipto na fazenda.

A unidade RQo + LAd5 representa o NEOSSOLO QUARTZARÊNICO Órtico típico em associação com o LATOSSOLO AMARELO Distrófico psamítico, este último caracterizado por apresentar textura arenosa, com menos de $15 \%$ de argila. Na área dos RQo foram identificadas diversas lagoas temporárias (de verão) de diferentes tamanhos, onde é possível identificar também o GLEISSOLO HÁPLICO. Estes indicam que as lagoas existem há tempo suficiente para que a gleização tenha desenvolvido esse solo.

Aparentemente, os solos da região são indicados como aptos à atividade agrícola, o que inicialmente não imporia restrições à silvicultura. Contudo, a identificação do caráter coeso, associado às condições climáticas regionais (déficit hídrico acentuado no inverno) podem apresentar-se como fatores de restrição local às culturas, permanecendo apenas as plantas mais resistentes. 


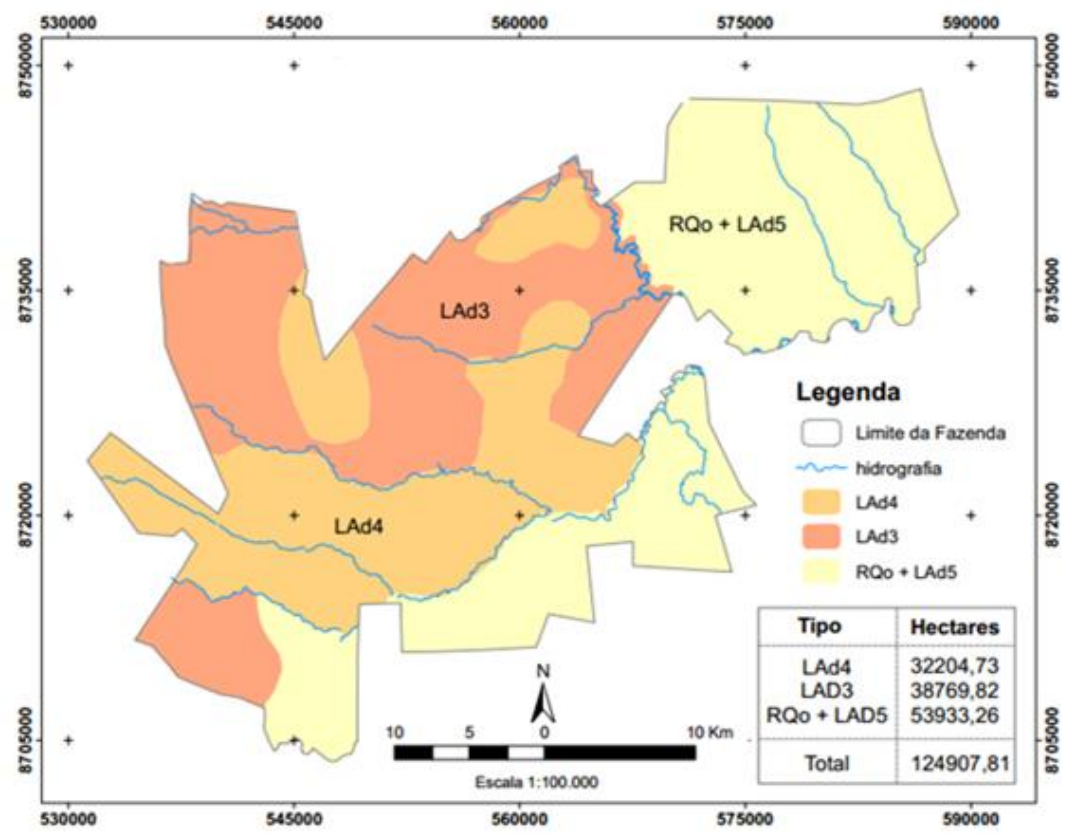

Figura 4. Mapa de solos da Fazenda Caracol. Os coesos foram identificados na classe LAd3.

\section{Agentes Cimentantes: Argila e Sílica}

Considerando estudos sobre solos coesos em áreas dos Tabuleiros Costeiros (Moreau, 2006; Corrêa et al., 2008; Lima Neto el al, 2010) que indicaram como um dos principais fatores na sua formação o maior teor de argila muito fina $(<0,2$ $\mu \mathrm{m})$ translocada do horizonte superficial para $\mathrm{o}$ horizonte subjacente, foi considerada por alterar algumas das suas outras propriedades como o aumento da densidade do solo e a diminuição da porosidade total. Considerando também o fato do caráter coeso se manifestar normalmente nos primeiros centímetros, entre os horizontes transicionais AB e BA (Jacomine, 2005), foram feitas, a partir desse pressuposto, interpolações referentes aos teores de argila, utilizando para isso os dados analíticos das 79 trincheiras analisadas no Relatório Técnico da Fazenda, como apresentado nas figuras 5 .

Além da argila, alguns autores (Steinhardte Franzmeier, 1979; Ibeiro, 1986) também discutem que o processo de coesão do solo pode ter relação com a presença de sílica. A interpolação dos teores de sílica obtida por ataque sulfúrico embora apenas para alguns perfis de solo da fazenda Caracol é apresentada na figura 6 . A interpolação foi restrita para as profundidades entre $100-200 \mathrm{~cm}$.

A figura 6 permite observar que os teores de sílica do ataque sulfúrico se concentram no setor centro-norte da fazenda Caracol, na mesma porção onde são identificados os solos com os maiores teores de argila em superfície e subsuperfície. Constata-se que, de modo geral, os menores teores de $\mathrm{SiO} 2$ situam-se nas extremidades sul, leste e norte da área, onde são registradas as menores altitudes. Supõe-se uma possível migração vertical das argilas, entupindo os poros do horizonte subsuperficial, promovendo a formação de horizontes adensados, embora friáveis quando úmidos, como típico dos Latossolos, mas causando uma hidromorfia suspensa e subsequente dissociação entre ferro e argila, seguida de uma possível dissolução da argila liberando $\mathrm{Si}$ e aumentando o Ki. Logo, a sílica liberada migraria em profundidade. Contudo, convém ressaltar que os aumentos de argila foram registrados no Latossolo Amarelo e a concentração de sílica nos Argissolos em posição topográfica mais baixa que os Latossolos.

Nesse sentido, é possível pensar-se então em migração lateral tanto da argila como da sílica nas vertentes situadas nas bordas dos interflúvios aplainados onde dominam os Latossolos, compondo sistemas pedológicos constituídos por Latossolos Amarelos-Argissolos Amarelos, de montante para jusante, hipótese não testada. Entretanto, a partir dos resultados de outro estudo (Ribeiro, 1986), espera-se ainda que a fonte desse enriquecimento de sílica possa também ser proveniente principalmente do processo de dissolução do quartzo. Mas, para uma melhor explicação são necessárias outras análises que mostrem qual o estágio atual desta sílica nos solos da fazenda. 


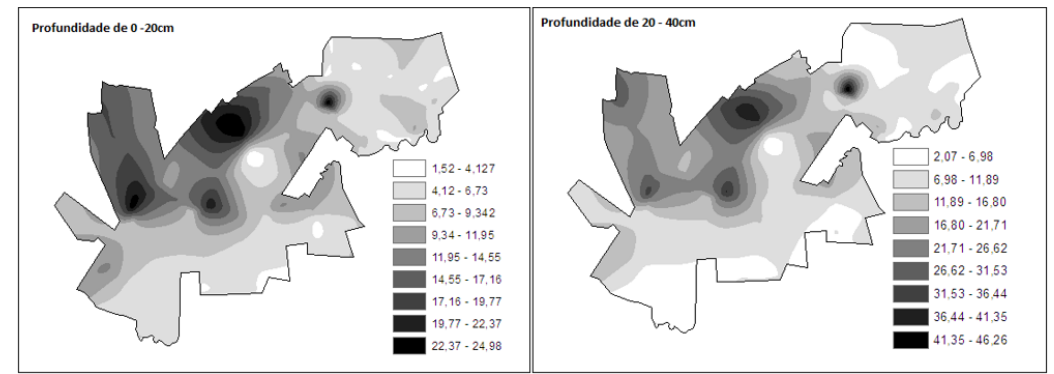

Figura 5: Interpolação dos teores de argila para as profundidades de $0-20 \mathrm{~cm}$ e $20-40 \mathrm{~cm}$.

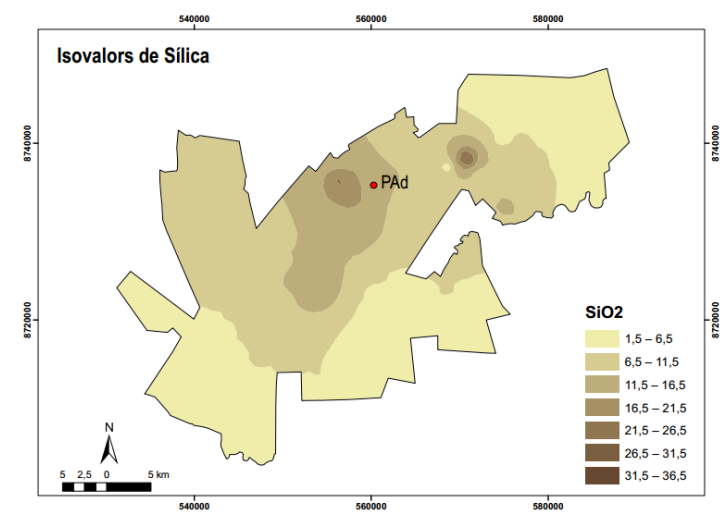

Figura6: Interpolação dos teores de sílica (SiO2) de ataque sulfúrico para as profundidades de $100-200 \mathrm{~cm}$, fazenda Caracol-BA. Em destaque o perfil PAd (ARGISSOLO AMARELO Distrocoeso petroplíntico) onde o caráter coeso foi identificado.

\section{Uso e Cobertura da Terra}

Apesar de estar localizada no Oeste da Bahia, nos limites da nova fronteira agrícola do país, a análise do uso e cobertura da terra da fazenda Caracol evidencia que esta área está com sua cobertura natural bem preservada, o que descartaria efeitos antrópicos na formação de horizontes coesos.

Nos quatro anos analisados $(1985,1995$, 2005 e 2013) observa-se que a mudança do uso e cobertura da terra dentro do recorte têmporoespacial selecionado é relativamente pequena (Figura 7). De acordo com relatos dos gestores da
Fazenda, essa área só começou a ser ocupada a partir de 2008, com a inserção dos primeiros experimentos de silvicultura, pastagem e agricultura irrigada.

A cobertura natural é formada por fitofisionomias do bioma Cerrado, como observado no mapa acima, foram identificadas as seguintes classes: Cerradão, Cerrado Típico, Cerrado Ralo e Formações Campestres. Na tabela 1 é apresentado os valores em porcentagens e distribuição em quilômetros quadrados das classes de cobertura natural e uso antrópico.
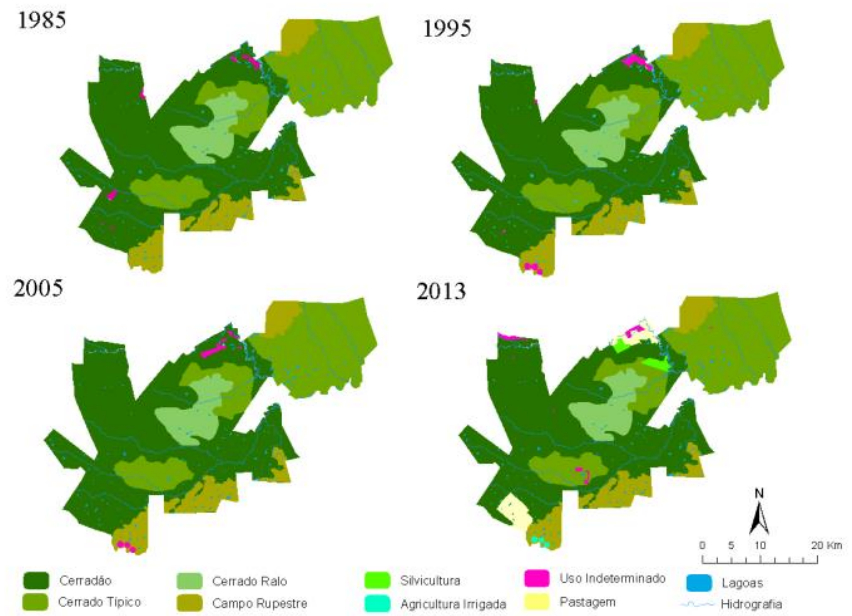

Figura 7: Sucessão histórica do uso e cobertura da terra da Fazenda Caracol-BA. Fonte: imagens Landsat. Elaborado por: Brasil, 2014. 
Tabela 1: Participação de cada classe de uso na área total da Fazenda.

\begin{tabular}{|c|c|c|c|c|c|}
\hline \multicolumn{3}{|c|}{1985} & \multicolumn{3}{|c|}{2005} \\
\hline Classe & $\mathbf{K m}^{2}$ & $\%$ & Classe & $\mathrm{Km}^{2}$ & $\%$ \\
\hline Uso Indeterminado & 6,54 & 0,52 & Uso Indeterminado & 8,22 & 0,66 \\
\hline Lagoas & 13,64 & 1,09 & Lagoas & 13,99 & 1,12 \\
\hline Cerradão & 665,74 & 53,31 & Cerradão & 666,52 & 53,37 \\
\hline Cerrado Ralo & 82,04 & 6,57 & Cerrado Ralo & 82,04 & 6,57 \\
\hline Cerrado Típico & 357,38 & 28,62 & Cerrado Típico & 357,38 & 28,62 \\
\hline Drenagens & 2,02 & 0,16 & Drenagens & 2,03 & 0,16 \\
\hline $\begin{array}{l}\text { Formações } \\
\text { Campestres }\end{array}$ & 121,44 & 9,72 & $\begin{array}{l}\text { Formações } \\
\text { Campestres }\end{array}$ & 118,75 & 9,51 \\
\hline Total & 1248,81 & 100 & Total & 1248,81 & 100 \\
\hline \multicolumn{3}{|c|}{1995} & \multicolumn{3}{|c|}{2013} \\
\hline Classe & $\mathbf{K m}^{2}$ & $\%$ & Classe & $\mathbf{K m}^{2}$ & $\%$ \\
\hline Uso Indeterminado & 9,72 & 0,78 & Uso Indeterminado & 4,93 & 0,4 \\
\hline Lagoas & 13,7 & 1,1 & Silvicultura & 15,84 & 1,27 \\
\hline Cerradão & 665,79 & 53,31 & Culturas Anuais & 2,8 & 0,22 \\
\hline Cerrado Ralo & 82,04 & 6,57 & Pastagem & 29,65 & 2,37 \\
\hline Cerrado Típico & 357,38 & 28,62 & Lagoas & 14,05 & 1,12 \\
\hline Drenagens & 1,92 & 0,15 & Cerradão & 628,03 & 50,29 \\
\hline $\begin{array}{l}\text { Formações } \\
\text { Campestres }\end{array}$ & 118,37 & 9,48 & Cerrado Ralo & 82,04 & 6,57 \\
\hline \multirow{4}{*}{ Total } & \multirow{4}{*}{1248,81} & \multirow{4}{*}{100} & Cerrado Típico & 350,45 & 28,06 \\
\hline & & & Drenagens & 2,03 & 0,16 \\
\hline & & & $\begin{array}{l}\text { Formações } \\
\text { Campestres }\end{array}$ & 118,75 & 9,51 \\
\hline & & & Total & 1248,81 & 100 \\
\hline
\end{tabular}

A classe de Cerradão é a que cobre maior área $(50,29 \%)$ do total da Fazenda, faz parte das Formações Florestais. De 1985 à 2013 essa classe perdeu $6,02 \%$ da sua área inicial, em função da ocupação antrópica para atividades como pecuária e silvicultura. Segundo o gerente da Fazenda, em 2008 foram realizados os primeiros experimentos com eucalipto na área. Os solos relacionados a essa fitofisionomia são geralmente profundos, bem drenados e correspondem aos Latossolos Amarelos, com textura areno-argilosa, o que lhe confere moderada suscetibilidade à erosão. A substituição da vegetação natural do Cerradão para implantação da cultura de eucalipto não foi bemsucedida, com alta taxa de mortandade da espécie. Estudos de solos na área do experimento permitiram a identificação do caráter coeso nestes solos. A manifestação da coesão no perfil variou muito, em alguns pontos foi identificado a partir de $1 \mathrm{~m}$ e em outros foi identificado nos primeiros $20 \mathrm{~cm}$ do solo (Brasil, 2011).

Apesar de ser identificado primeiramente no setor de ocorrência do Cerradão, os perfis com o caráter coeso ocorrem também na área de transição entre Cerradão, Cerrado Típico e Cerrado Ralo, topograficamente mais baixos que os Brasil, J.; Castro, S. S. anteriores. Quanto à localização do caráter coeso no perfil, percebeu-se que nas áreas de Cerrado Ralo sem presença de serapilheira nem a formação do estrato vegetal rasteiro o caráter coeso ocorre nos primeiros centímetros, essas características estão relacionadas a menor profundidade efetiva desses solos e ao estresse radicular provocado pelo horizonte adensado.

A segunda classe com maior representatividade é o Cerrado Típico, que faz parte das Formações Savânicas, entendida como uma classe intermediária entre Cerrado Denso e Cerrado Ralo, que ocupa atualmente $28,06 \%$ da área da fazenda. Essa classe perdeu menos de $1 \%$ da sua área de ocorrência entre o período analisado, sendo substituída pela atividade de silvicultura. Nela não há perfis de solos coesos.

A classe de Cerrado Típico ocorre também sobre Latossolos, mas principalmente sobre o Neossolo Quartzarênico Órtico típico, a nordeste da Fazenda. Nessas áreas as cores claras e esbranquiçadas dos Neossolos são facilmente identificadas, com ocorrência expressiva de plantas espinhosas. Mas neles não se observou perfis de solos coesos. 
A classe Cerrado Ralo ocorre em 6,57\% da área e durante o período analisado não houve alteração dessa fitofisionomia. Solos que ocorrem nesse tipo de vegetação apresentam, geralmente, restrições quanto ao desenvolvimento radicular, predominando espécies com sistema radicular superficial. A formação dessa fitosifionomia, entretanto, pode ter relação com a reduzida profundidade efetiva desses solos, que pode ser resultado de agentes cimentantes como a sílica.

As Formações Campestres ocorrem em 9,51\% da área de pesquisa, formada sobre Latossolos Amarelos e Neossolos Quartzarênicos, localizadas no setor sudeste da fazenda. A partir do ano de 2008 foram realizados experimentos agrícolas de agricultura irrigada. Nesse setor da fazenda não houve problemas nos cultivos e nem identificado o caráter coeso no solo.

Como observado na figura da evolução do uso e cobertura da terra, existe na área de estudo uma quantidade considerável de lagoas distribuídas por todos os setores da fazenda, que representam $1,12 \%$ da área total. Segundo Alves (2011) a formação dessas lagoas está relacionada ao processo de deflação, que ocorreu em períodos quando clima da região era mais seco e quente (entre 7,5Ka AP e 4Ka AP).

Mesmo com vegetação natural bem preservada, observa-se que entre 1995 à 2013 novos usos são introduzidos na área. De acordo com os gestores da Fazenda, espera-se que nos próximos dez anos sejam implantados novos experimentos de culturas anuais, infraestrutura para pecuária extensiva, silvicultura e atividades integradas de lavoura-pecuária. Nas áreas onde o experimento de eucalipto foi malsucedido, em função do horizonte coeso que dificultou o crescimento radicular, atualmente é encontra-se a pecuária bovina extensiva de corte.

\section{Síntese dos Parâmetros}

Em síntese, as principais características de cada parâmetro estudado estão apresentadas no quadro 2. A partir deste, foi realizado um exercício, tomando como os principais parâmetros os dados interpolados de argila e $\mathrm{SiO} 2$ (do ataque sulfúrico) como seu reflexo, o qual permitirá estimar a área de ocorrência de solos coesos na área de pesquisa, conforme apresentado na figura 8 .

Os solos coesos na área pesquisada seriam, portanto, de dois tipos, resultantes do acúmulo de argila nos horizontes subsuperficiais dos solos, que causam seu adensamento e coesão, os quais seriam os solos reconhecidos como coesos. $\mathrm{E}$ os resultantes de cimentação por sílica, fato este que ocorreria apenas em profundidade, embora na mesma posição dos anteriores, sugerindo relação entre os dois fenômenos. Nesse sentido, não há compatibilidade clara com o caráter coeso proposto pelo SiBCS (Embrapa, 2013).

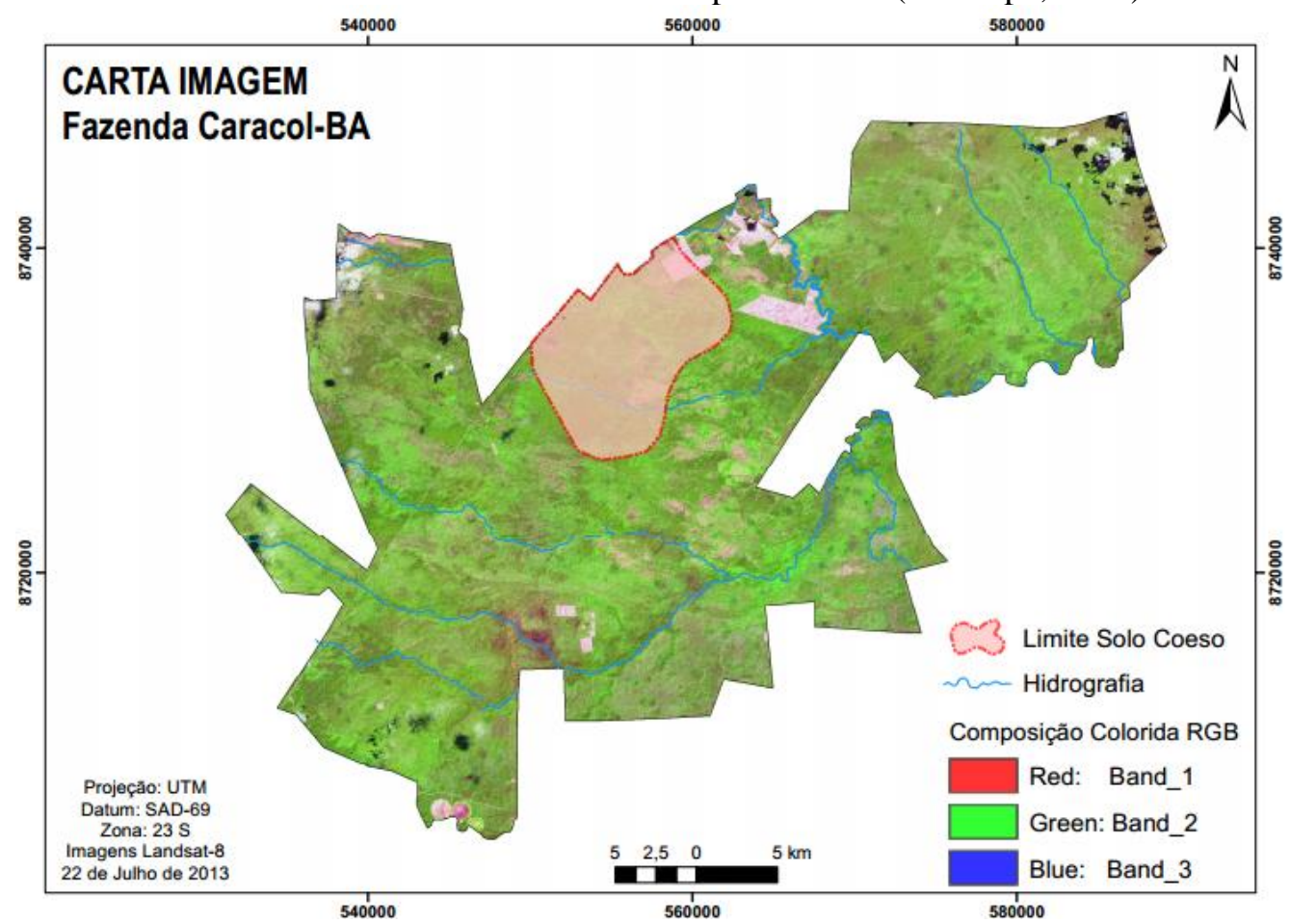

Figura 8: Mapa com limite de ocorrência potencial a manifestação do caráter coeso nos solos na fazenda Caracol.

Quadro 2:Síntese das principais características dos parâmetros ambientais analisados no estudo dos solos coeso da fazenda Caracol-BA. 


\begin{tabular}{|c|c|}
\hline $\begin{array}{c}\text { Parâmetros } \\
\text { Físico-Ambientais } \\
\end{array}$ & Características \\
\hline Geologia & $\begin{array}{l}\text { A unidade predominante em toda a fazenda é a denominada de Depósitos detrito-lateríticos } \\
\text { provenientes de processos de lateritização em rochas de composições diversas sem a presença } \\
\text { de crosta. Os sedimentos dessa unidade são essencialmente cauliníticos. }\end{array}$ \\
\hline Hipsometria & $\begin{array}{l}\text { Baixo gradiente altimétrico em função principalmente do processo de pediplanação que } \\
\text { rebaixou as superfícies do relevo dessa área. }\end{array}$ \\
\hline Declividade & $\begin{array}{l}\text { Predominância de formas de relevo plano e suave ondulado. Com exceção as áreas próximas } \\
\text { aos canais, onde o relevo é mais dissecado. }\end{array}$ \\
\hline Solos & $\begin{array}{c}\text { Os Latossolos Amarelas são os solos mais expressivos na área. Uma das características } \\
\text { desses solos é a coesão manifestada entre os horizontes A e B. O adensamento do solo pode } \\
\text { estar relacionado entre outros fatores ao entulhamento de partículas finas de argilas } \\
\text { translocadas por iluviação. }\end{array}$ \\
\hline $\begin{array}{l}\text { Agentes } \\
\text { Cimentantes }\end{array}$ & $\begin{array}{l}\text { De modo geral, os solos da fazenda Caracol apresentam textura areno-argilosa, alguns setores } \\
\text { da fazenda são identificados teores de argilas acentuados entre os primeiros centímetros do } \\
\text { solo. O acúmulo de partículas finas pode estar contribuindo no adensamento desses solos. Em } \\
\text { profundidade de } 100 \mathrm{~cm} \text {, percebe-se, entretanto, a concentração de teores de } \mathrm{SiO}_{2} \text { seguindo o } \\
\text { mesmo padrão da argila em superfície. }\end{array}$ \\
\hline $\begin{array}{l}\text { Uso e Cobertura } \\
\text { da Terra }\end{array}$ & $\begin{array}{l}\text { Avegetação da área está bastante preservada, contendo mais de } 80 \% \text { da sua cobertura natural, } \\
\text { o que exclui em definitivo possíveis interpretações baseadas em influência antrópica na } \\
\text { instabilização dos constituintes argiloso e sua translocação, tratando-se mais provavelmente } \\
\text { de reações associadas ao clima e às reações químicas consequentes. }\end{array}$ \\
\hline
\end{tabular}

A ocorrência potencial dos solos coesos representa pouco, cerca de $5 \%$ da área total da fazenda. Entretanto, essa ocorrência pode vir a contribuir para o uso e manejo dos solos da Fazenda, uma vez que pode se ter um manejo melhor adequado, que dê prioridade a culturas das quais as raízes não precisem ultrapassar o horizonte adensado.

De acordo com os gestores da fazenda, a previsão é de que nos próximos dez anos, novos experimentos agrícolas sejam implantados na fazenda Caracol, e para evitar novos problemas como a mortandade dos eucaliptos, o conhecimento dos aspectos físicos da paisagem são relevantes no entendimento do solo e melhor manejo dessa área, diante suas potencialidades e limitações. Para isso são necessárias outras análises de maior detalhe, que passe da escala macro para uma análise micro dos atributos do solo, principalmente no tocante as análises micromorfológicas.

\section{Conclusões}

Observou-se que a análise do relevo não permitiu identificar padrões que justificassem ou explicassem a presença dos solos coesos na área da Fazenda Caracol-BA, embora tenham sido eficientes para distinguir Latossolos e Neossolos.

Por sua vez, a interpolação dos teores de argila para as profundidades de $0-20 \mathrm{~cm}$ e $20-40 \mathrm{~cm}$ se mostraram de grande importância na delimitação de uma área possível de ocorrência dos solos coesos, os quais apontam na direção de caráter coeso associado ao enriquecimento de argila em subsuperfície. Os maiores teores de argila foram identificados no setor centro-norte da Fazenda. E correlacionados, sobretudo, aos Argissolos Amarelos.

\section{Agradecimentos}

As autoras agradecem ao Conselho Nacional de Desenvolvimento Científico e Tecnológico - CNPq pelo financiamento da bolsa de mestrado à primeira autora e a empresa Granflor Gestão Empreendimentos Florestais por disponibilizar dados físico-químicos dos solos da Fazenda Caracol-BA.

\section{Referências}

Alves, R. R. 2011.Gênese e evolução da paisagem quaternária no médio São Francisco: fatos e evidências na bacia do rio Grande-Bahia. 2011, 298f, Tese (Doutorado em Geografia), Universidade Federal de Uberlândia, Uberlândia-MG.

Anjos, L.H.C. 1985. Caracterização, gênese, classificação e aptidão agrícola de uma seqüência de solos do Terciário na região de Campos-RJ. Itaguaí, Universidade Federal Rural do Rio de Janeiro, 194p. (Tese de Mestrado).

Araújo Filho, J. C. 2003. Horizontes cimentados em Argissolos e Espodossolos dos Tabuleiros Costeiros e em Neossolos Regolíticos e Planossolos da Depressão Sertaneja do Nordeste do Brasil. Universidade de São Paulo. Instituto de Geociências da USP - SP, 233p. (Tese de Doutoramento). 
Brasil, J. 2011. Classificação e Mapeamento de Solos na Depressão do São Francisco-BA: carta SC 23-Z-C-II-3-SO. 10 de janeiro de 2012 96f. Monografia (Graduação em Geografia), Universidade Federal da Bahia, Barreiras-BA.

Brasil, J. 2014. Parâmetros Físico-Ambientais para Compartimentação Geoambiental e Delimitação da Ocorrência de Solos Coesos na Depressão do São Francisco, BA. 09 de setembro de 2014. 136 f. Dissertação (Mestrado). Universidade Federal de Goiás, Goiânia-GO.

Corrêa, M. M.; Ker, J. C.; Barrón, V.; Torrent, J.; Curi, N.; Torres, T. C. P. 2008. Caracterização física, química, mineralógica e micromorfológica de horizontes coesos e fragipãs de solos vermelhos e amarelos do ambiente tabuleiros costeiros. Revista Brasileira de Ciências do Solo, 32:297-313.

Fonseca, O.O.M. 1986. Caracterização e classificação de solos latossólicos e podzólicos desenvolvidos nos sedimentos do Terciário no litoral brasileiro. Itaguaí, 185p. Dissertação (Mestrado) - Universidade Federal Rural do Rio de Janeiro.

Giarola, N.F.B. 2002. Similaridades entre solos coesos e hardsetting: Caracterização do comportamento físico. 65p. Tese (Doutorado em Agronomia), Escola Superior de Agricultura Luiz de Queiroz, Piracicaba-SP.

Jacomine, P.K.T. 1996. Distribuição geográfica, característica e classificação dos solos coesos dos Tabuleiros Costeiros. In: Reunião Técnica Sobre Solos Coesos Dos Tabuleiros Costeiros, Cruz das Almas, 1996. Anais. Aracaju, EMBRAPA-CPATC \& CNPMF / EAUFBA / IGUFBA, p.13-26.
Ker, J.C. 1997. Latossolos do Brasil: Uma revisão. Geonomos, 5(1):17-40.

Lima Neto, J. A.; Ribeiro; M.R.; Corrêa; M.M.; Souza-Júnior, V. S.; Araújo Filho; J. C.; Lima, J. F. W.F,. 2010. Atributos químicos, mineralógicos e micromorfológicos de horizontes coesos de Latossolos e Argissolos dos Tabuleiros Costeiros do Estado de Alagoas. Revista Brasileira de Ciência do Solo v.34 n.2.

Moreau, A. M. S. S., Costa, L. M da, Ker, J. C., Gomes, F. H. 2006. Gênese de horizonte coeso, fragipã e duripã em solos do tabuleiro costeiro do sul da Bahia. Revista Brasileira de Ciência do Solo, 30:1021-1030, Disponível em: http://www.scielo.br/pdf/rbcs/v30n6/a11v30n6. pdf $>$. Acessado em: 20 de setembro de 2011.

Nunes, F. C.; Silva, E. F. da; Vilas-Boas, G. da S. 2011. Grupo Barreiras: características, gênese e evidências de neotectonismo. Rio de Janeiro: Embrapa Solos, 31 p. (Embrapa Solos. Boletim de Pesquisa e Desenvolvimento, n. 194).

Raij, B. van; Camargo, O.A. 1973. Súlica solúvel em solos. Bragantia, v.32, p.223-236.

Rezende, J. de O. 2000. Solos coesos dos Tabuleiros Costeiros: limitações agrícolas e manejo. Salvador: SEAGRI, SPA, 117p. (Série Estudos Agrícolas, 1).

Ribeiro, L.P. 1986. Sílica em horizontes coesos de solos da Bahia. Universitas, n.38, p.59-80.

Ribeiro, M.R. 2001a. Características morfológicas dos horizontes coesos dos solos dos Tabuleiros Costeiros. In: Workshop Coesão Em Solos Dos Tabuleiros Costeiros, Aracaju, 2001. Anais. Aracaju: Embrapa Tabuleiros Costeiros 161168.

Steinhardt, G. C. Franzmeier, D. P. 1979. Chemical and mineralogical properties of the fragipãs of the Cincinnati catena. Soil Sci. Soc. Am. J., v. 43, p $1008-1113$. 